\title{
Uma proposta de modelo analítico para a inovação na gestão pública ${ }^{1}$
}

Dany Flávio Tonelli

Universidade Federal de Lavras (UFLA)

Samantha Thais Baião Moreira

Universidade Federal de Lavras (UFLA)

Iasmim Mesquita

Universidade Federal de Lavras (UFLA)

Stephania Rezende Silva

Universidade Federal de Lavras (UFLA)

Maria Olívia Silva e Vasques

Universidade Federal de Lavras (UFLA)

É crescente a necessidade de adoção de práticas inovadoras na administração pública. A partir disso, objetivou-se realizar um estudo exploratório acerca da inovação no setor público, iniciando a construção de arcabouço teórico que culmine na criação de categorias condizentes às especificidades do setor público. Elucidadas as tipologias gerais encontradas, propõe-se um diagrama analítico de cruzamento entre as Gerações de Inovação (CoELHo, 2012) e os tipos de inovações resultantes de adaptação orgânica (serviço, arranjos organizacionais e arranjos institucionais). Como implicação possível, menciona-se a abertura de possibilidades para compreensão das diferentes ações inovativas relacionadas ao setor público, como proposto em análise das iniciativas do Concurso Inovação na Gestão Pública Federal da Enap.

Palavras-chave: inovação, administração pública, prestação de serviços, desenvolvimento organizacional

\footnotetext{
1 Registram-se agradecimentos ao CNPq pelo apoio financeiro que viabilizou a realização deste trabalho.
}

[Artigo recebido em 10 de junho de 2015. Aprovado em 9 de novembro de 2015.] 
Una propuesta de modelo analítico para la innovación en la gestión pública

Hay una creciente necesidad de adoptar prácticas innovadoras en la gestión pública. Por ello, se tuvo como objetivo realizar un estudio exploratorio sobre la innovación en el sector público, a partir de la construcción del marco teórico que culmina en la creación de categorías adecuadas as las especificidades del sector público. Dilucidadas las tipologías generales encontradas, se propone un esquema analítico de un cruce entre las Generaciones de Innovación (COELHO, 2012) y los tipos de innovaciones resultantes de la adaptación orgánica (servicio, arreglos organizacionales y arreglos institucionales). Como posible implicación se menciona la apertura de posibilidades para la comprensión de las diferentes acciones innovadoras relacionadas con el sector público como se propone en el análisis de las iniciativas del Concurso Inovação na Gestão Pública Federal de Enap.

Palabras clave: innovación, administración pública, prestación de servicios, desarrollo organizacional

\section{An analytical model proposal for innovation in public administration}

There is a growing need to adopt innovative practices in public administration. From that aimed to conduct an exploratory study on innovation in the public sector, starting the construction of theoretical framework that culminates in the creation of consistent categories to specific public sector. Elucidated the general types found, we propose an analytical diagram of a cross between the Innovation Generation (COELHO, 2012) and the types of innovations resulting from organic adaptation (service, organizational arrangements and institutional arrangements). As a possible implication is mentioned the opening of possibilities for understanding the different innovative actions related to the public sector as proposed in the analysis of Innovation Competition initiatives in Public Management of Federal Enap.

Keywords: innovation, public administration, service delivery, organizational development 


\section{Introdução}

Considerando as relações entre Estado, sociedade e mercado, o contexto atual emoldura a adoção de práticas mais dinâmicas e inovadoras no âmbito da administração pública. A complexidade dos ambientes governamentais torna obsoleto o modelo mecanicista representado pela administração burocrática, abrindo espaço para práticas da administração privada, agora adaptadas na chamada Nova Gestão Pública (OSBORne; GAebler, 1994). Seguindo tendências de países como Reino Unido, Nova Zelândia e EUA, a partir de 1995, reestruturase a administração pública brasileira com base nos pressupostos da Nova Gestão Pública, enfatizando a necessidade de profissionalização dos servidores, o controle de resultados, a descentralização administrativa, a flexibilização de rotinas e procedimentos e a distinção entre atividades exclusivas e não exclusivas do Estado (BRESSER PereirA, 1997; JUNQUilho, 2010).

Há de se notar, no entanto, que o reconhecimento da indispensabilidade de práticas inovadoras se dá desde Adam Smith e List, no século 18, que relacionavam o conceito de "desenvolvimento" com a acumulação de descobertas e melhorias (ANDREASSI, 2007). Porém, é apenas no século 20 que Schumpeter (1982) desenvolve uma teorização sólida a respeito da inovação. Conforme afirmam Brandão e Bruno-Faria (2013), Schumpeter descreve a inovação como as novas combinações entre materiais e forças produtivas que viabilizam produtos inéditos e, consequentemente, o desenvolvimento econômico. Esse processo é chamado de "destruição criativa" e envolve a substituição de tecnologias, introduzindo novos ciclos de desenvolvimento econômico.

No que tange ao setor público, entretanto, o estudo desse tema se restringe em sua maioria à análise de casos concretos, sendo por vezes esquecida sua dimensão conceitual e teórica (BRANDÃO; BRUNO-FARIA, 2013). Ainda prescindimos de abordagens teóricas que tenham como finalidade compreender a inovação no contexto público. Como bem apontam Lima e Vargas (2012), o setor público é visto tão somente como regulador, financiador e consumidor de produtos inovadores gerados pelo setor privado, esse, sim, considerado protagonista do processo de inovação. Esse fato indica uma lacuna da literatura ainda pouco explorada: a necessidade de maior compreensão sobre a inovação no setor público, suas categorias e características peculiares.

Sob essa ótica, estabelece-se o objetivo do presente trabalho de realizar um estudo exploratório da inovação no setor público, iniciando a construção de um modelo analítico que culmine na identificação de tipologias e criação de categorias de inovação específicas para esse setor. $O$ estudo se faz pertinente na medida em 
que colabora para a construção de uma visão mais orgânica a respeito do tema, a qual é imprescindível para o desenvolvimento sustentável das organizações públicas atuais, que crescentemente se deparam com novas demandas da sociedade.

A investigação foi construída em duas etapas. Na primeira são definidas duas diretrizes. Uma é dedicada à revisão conceitual do tema inovação no setor público. Outra resgata as tipologias já existentes na literatura e posterior estabelecimento de relações entre os conceitos. Como critério para a seleção dos textos dessa primeira etapa, foram buscadas na literatura, entre os anos de 2005 e 2013, definições conceituais acerca da inovação no setor público. Os descritores utilizados para a localização dos artigos foram "inovação" e "setor público". Como bases de dados, optou-se pela Rede de Revistas da América Latina, Caribe, Espanha e Portugal (Redalyc) e pela base do Scielo, escolhidas devido à sua abrangência e incidência equilibrada de artigos nacionais e internacionais. A segunda etapa acomoda as discussões acerca das inovações de primeira, segunda e terceira geração (COELHO, 2012) e as categorias desenvolvidas no corpo deste trabalho. O produto desse cruzamento é uma matriz conceitual que busca promover embasamento explicativo para as atividades que envolvem tanto o Estado, como as relações que ele estabelece com a sociedade e o mercado.

\section{Inovação no setor público}

Barlach (2012, p. 192) extrai do Concurso Inovação na Gestão Pública Federal da Enap (BRASIL, 2015) o seguinte conceito de inovação: "mudança em práticas anteriores, por meio da incorporação de novos elementos da gestão pública ou de uma nova combinação dos mecanismos existentes, que produzam resultados positivos para o serviço público e para a sociedade". Consonante com essa ideia, para Alberti e Bertucci (2006) inovar é o ato de conceber e implementar meios de alcançar um resultado, envolvendo incorporação de novos elementos, uma nova combinação de elementos existentes ou mudança significativa quanto ao afastamento da forma tradicional de fazer as coisas: refere-se a produtos, políticas e programas, abordagens e processos. A importância que o assunto adquire na administração pública atual evidencia-se por meio do Plano Diretor de Reforma do Estado, marco da instituição de práticas gerenciais no País. Para assegurar e facilitar a realização das funções demandadas pela sociedade, afirma-se que é necessária a adoção de mecanismos inovadores de operação e funcionamento (BRASIL, 1995). Sandamas (2005), citando Mulgan e Albury (2003), reforça a ideia de inovação no setor público como implementação de processos, produtos, serviços; porém, distinguindo as inovações de sucesso como aquelas que resultam em melhorias nos resultados de eficiência, efetividade 
e qualidade. Já para Baracchini (2002), a inovação pública é vista, sobretudo, pela perspectiva da esfera local, como uma reorganização e reestruturação dos valores da administração pública. Farah (2008) também aborda a inovação no âmbito local, enfatizando, entretanto, fatores que influenciam a disseminação de inovações nesses governos.

Em outro aspecto a ser analisado, conforme aponta Lima e Vargas (2012), os autores Koch e Hauknes (2005) adicionam ao conceito de inovação no setor público o caráter contextual, o qual considera inovação como "implementação ou desempenho de uma nova forma específica ou repertório de ação social, implementada deliberadamente por uma entidade no contexto dos objetivos e funcionalidades de suas atividades" (LIMA; VARGAS, 2012, p. 386). Interessante notar que Spink (2003) atribui a inviabilidade de existência de um consenso acerca do conceito de inovação no setor público justamente a esse fator: o contexto. Para o autor, antes de se analisar a concepção do que vem a ser inovação na gestão pública, é preciso entender as circunstâncias nas quais ela se desenvolve.

Para fins deste artigo, de maneira sintetizada, entende-se por inovação no setor público a ideia de mudança, introdução de novidade em relação ao modo antigo de se fazer as coisas em determinado contexto público. A inovação deve também gerar valor para a sociedade e usuários, de modo que a exploração bem-sucedida de uma ideia culmine em mudança positiva, consistente e duradoura para as pessoas.

\section{Sistematização das tipologias existentes}

Por meio do estudo proposto, percebe-se que o conceito de inovação é bastante difundido, especialmente na bibliografia econômica, quando se discute o papel das empresas, a importância da competitividade e as dinâmicas do capitalismo. Portanto, a literatura tem atribuído um foco importante sobre a inovação no setor privado, o que produz impactos não negligenciados em aspectos macroeconômicos que interferem nas condições do Estado de conduzir sua política fiscal e financeira.

Em relação ao setor público, distintamente das já difundidas tipologias de inovação em âmbito privado, é necessário um consenso no que tange à formulação desses tipos. Em parte porque se nota grande variedade de atores que diferem conforme seus interesses, demandando do Estado posicionamentos diferenciados e exclusivos. Entretanto, assim como afirmam Lima e Vargas (2012), é desejável obter estabilidade na classificação das inovações, visto que isso possibilitaria sua medição em estudos agregados e comparativos. A seguir, elencam-se os principais tipos de inovação encontrados na literatura referentes ao setor público. 
Tabela 1 - Tipologias de inovação no setor público

\begin{tabular}{|c|c|c|}
\hline Tipo & Definição & Autores \\
\hline $\begin{array}{l}\text { Inovação de } \\
\text { produto }\end{array}$ & $\begin{array}{l}\text { Introdução de bem novo ou significativa- } \\
\text { mente melhorado comparado com os ser- } \\
\text { viços e bens já existentes na organização. }\end{array}$ & $\begin{array}{l}\text { Bloch (2010), citado } \\
\text { por Brandão e Bruno- } \\
\text { Faria (2013); Hartley } \\
\text { (2005). }\end{array}$ \\
\hline $\begin{array}{l}\text { Inovação de } \\
\text { serviço }\end{array}$ & $\begin{array}{l}\text { Novas formas de prestação de serviços } \\
\text { aos usuários. }\end{array}$ & Hartley (2005). \\
\hline $\begin{array}{l}\text { Inovação em } \\
\text { comunicação }\end{array}$ & $\begin{array}{l}\text { Implementação de um novo método de } \\
\text { promoção da organização ou de seus } \\
\text { serviços e bens, ou novos métodos para } \\
\text { influenciar o comportamento de indivídu- } \\
\text { os ou outras organizações. }\end{array}$ & $\begin{array}{l}\text { Bloch (2010), citado } \\
\text { por Brandão e Bruno- } \\
\text { Faria (2013). }\end{array}$ \\
\hline $\begin{array}{l}\text { Inovação de } \\
\text { processo }\end{array}$ & $\begin{array}{l}\text { Implementação de método de produção } \\
\text { ou entrega de serviços ou bens novo ou } \\
\text { significativamente melhorado, comparado } \\
\text { com os processos já existentes na organi- } \\
\text { zação. Foco na melhoria da qualidade dos } \\
\text { serviços públicos. }\end{array}$ & $\begin{array}{l}\text { Bloch (2010), citado } \\
\text { por Brandão e } \\
\text { Brandão e Bruno- } \\
\text { Faria (2013); Alberti } \\
\text { e Bertucci (2006); } \\
\text { Hartley (2005). }\end{array}$ \\
\hline $\begin{array}{l}\text { Inovação } \\
\text { organizacional }\end{array}$ & $\begin{array}{l}\text { Implementação de novo método organi- } \\
\text { zacional ou gerencial que difere significa- } \\
\text { tivamente dos métodos já existentes na } \\
\text { organização; novos processos ou técnicas } \\
\text { de gerenciamento na administração } \\
\text { pública. }\end{array}$ & $\begin{array}{l}\text { Bloch (2010), citado } \\
\text { por Brandão e Bruno- } \\
\text { Faria (2013); Alberti e } \\
\text { Bertucci (2006). }\end{array}$ \\
\hline $\begin{array}{l}\text { Inovações } \\
\text { institucionais }\end{array}$ & $\begin{array}{l}\text { Foco na renovação das instituições } \\
\text { estabelecidas e/ou criação de novas } \\
\text { instituições. }\end{array}$ & $\begin{array}{l}\text { Alberti e Bertucci } \\
\text { (2006). }\end{array}$ \\
\hline $\begin{array}{l}\text { Inovações } \\
\text { conceituais }\end{array}$ & $\begin{array}{l}\text { Foco na introdução de novas formas de } \\
\text { governança (formulação interativa de po- } \\
\text { líticas, participação popular, entre outras). }\end{array}$ & $\begin{array}{l}\text { Alberti e Bertucci } \\
\text { (2006); Hartley } \\
\text { (2005). }\end{array}$ \\
\hline $\begin{array}{l}\text { Inovação } \\
\text { econômico- } \\
\text { financeira }\end{array}$ & $\begin{array}{l}\text { Orientação para eficiência, "fazer mais } \\
\text { com menos"; reformas e inovação de } \\
\text { primeira geração. Tem como princípios a } \\
\text { economicidade e a produtividade e cria- } \\
\text { ção de valor para o contribuinte. }\end{array}$ & Coelho, F. S. (2012). \\
\hline $\begin{array}{l}\text { Inovação } \\
\text { administrativo } \\
\text {-institucional }\end{array}$ & $\begin{array}{l}\text { Orientação para eficácia, "fazer o certo"; } \\
\text { reformas e inovação de segunda geração. } \\
\text { Tem como princípio a qualidade (percebi- } \\
\text { da) e criação de valor para o usuário. }\end{array}$ & Coelho, F. S. (2012). \\
\hline $\begin{array}{l}\text { Inovação } \\
\text { sociopolítica }\end{array}$ & $\begin{array}{l}\text { Orientação para efetividade, "fazer dife- } \\
\text { rença"; reformas e inovação de terceira } \\
\text { geração. Tem como princípios a equidade } \\
\text { e participação e criação de valor para o } \\
\text { cidadão. }\end{array}$ & Coelho, F. S. (2012). \\
\hline
\end{tabular}




\begin{tabular}{l|l|l}
\hline Tipo & Definição & Autores \\
\hline $\begin{array}{l}\text { Inovação de } \\
\text { posição }\end{array}$ & $\begin{array}{l}\text { Mudança no contexto, novos usuários, em } \\
\text { que produto/serviços são introduzidos. }\end{array}$ & Hartley (2005). \\
\hline $\begin{array}{l}\text { Inovação } \\
\text { estratégica }\end{array}$ & Novas metas e propósitos da organização. & Hartley (2005). \\
\hline $\begin{array}{l}\text { Inovação } \\
\text { retórica }\end{array}$ & Nova linguagem e novos conceitos. & Hartley (2005). \\
\hline
\end{tabular}

Fonte: Elaborado pelos autores.

Há de se especificar as categorias criadas pelo Concurso Inovação na Gestão Pública Federal, promovido pela Escola Nacional de Administração Pública (ENAP, 2014), que podem ser consideradas tipologias de inovação no setor público. Entretanto, a classificação criada pelo concurso é produto de uma abordagem prática, sendo as categorias nomeadas e propostas a partir de evidências empíricas dos casos inscritos ${ }^{2}$.

\section{Proposição de um diagrama analítico para inovação no setor público}

A partir do estudo dos conceitos e tipologias encontradas, vislumbra-se a possibilidade de estabelecer ligação entre esses tipos identificados a partir da revisão teórica e as dimensões de eficiência, eficácia e efetividade apontadas por Coelho (2012), que, respectivamente, caracterizam as inovações de primeira, segunda e terceira geração. Coelho (2012) aponta três gerações de reformas inovadoras no Brasil: uma visando à economia de recursos e maior eficiência, a segunda com orientação para a eficácia administrativa e a terceira geração, ainda dando seus primeiros passos, que introduz valores de gestão social, sobretudo a democracia participativa, em processos decisórios das políticas públicas.

Sob o foco dos 3Es (eficiência, eficácia e efetividade), é possível acomodá-los nos diferentes modelos históricos de administração pública do Brasil. Assume-se que, em cada um dos modelos administrativos - burocrático, gerencial e recente encaminhamento para versões mais participativas, como a governança pública (LÖFFER, 2001; SECHI, 2009; SILVA et al., 2013) e a gestão societal (PAULA, 2005) há a primazia de um dos três elementos sobre os outros, ainda que todos sejam buscados paralelamente. Para demonstrar essa afirmação, é importante traçar um breve histórico correlacionando eficiência, eficácia e efetividade com os modelos de gestão pública.

\footnotetext{
2 As categorias criadas pela Enap são as seguintes: "Melhoria dos processos de trabalho", "Atendimento ao cidadão, planejamento, gestão e desempenho institucional, inclusão social, gestão e desenvolvimento de pessoas, Gestão da informação, avaliação e monitoramento de políticas públicas e arranjos institucionais para coordenação e implementação de políticas públicas (intra e intergovernamental)" (ENAP, 2014).
} 
O modelo burocrático descrito por Weber pressupõe a organização racional e eficiente. Segundo Osborne e Gaebler (1994, p.13), no início do século 20, "a burocracia trouxe ao trabalho do governo a mesma lógica que a linha de montagem deu ao processo industrial". Assim, o modelo burocrático de gestão primou pela busca da eficiência por meio de instrumentos como a autoridade hierárquica e a especialização funcional, de modo a construir estrutura enxuta, capaz de impor uma dinâmica de uso racional dos recursos. Assim como sinaliza Secchi (2009), por um lado, os valores da eficiência econômica impõem a alocação racional dos recursos, que na teoria weberiana é traduzida em uma preocupação especial com a alocação racional das pessoas dentro da estrutura organizacional. Por outro, o valor da eficiência administrativa induz à obediência às prescrições formais das tarefas. Entretanto, bem como aponta Aragão (1997), Weber indicou ser objetivo da burocracia alcançar os fins do Estado, ou seja, a efetividade. Nota-se, assim, a coexistência dos indicadores apesar da atenção especial à eficiência. A partir do final da década de 1970 e início de 1980, com a crise fiscal e financeira decorrente da falência do modelo intervencionista de Estado, o discurso da nova gestão pública adquiriu proeminência. Ele se sustentava na crítica de que o Estado burocrático havia se desenvolvido em circunstâncias distintas do mundo moderno. Conforme destaca Motta (2013), a Nova Gestão Pública se orientava na administração privada como exemplo de eficiência e eficácia. Por outro lado, a burocracia foi considerada autorreferida e distanciada da necessidade das pessoas (OSBORNE; GAEBLER, 1994). A nova gestão pública, por meio de enfoques como governo descentralizado e voltado para o alcance de objetivos, valorizou a eficácia governamental. Conforme aponta Morais (s.d), "não é suficiente usar com economia, zelo e dedicação os bens e os recursos públicos, mas também se faz necessária a eficácia, o comprometimento político e institucional com um planejamento competente que ocasione a obtenção dos resultados sociais aspirados pela sociedade (...)".

O modelo gerencial, porém, é alvo de opiniões controversas. Segundo Paula (2005, p. 22), a nova administração pública mantém a dicotomia entre as dimensões política e administrativa, visto que esse modelo "adere a uma dinâmica administrativa que reproduz a lógica centralizadora das relações de poder e restringe o acesso dos cidadãos ao processo decisório". Assim, como alternativa a esse descompasso entre processo gerencial e política, a proposta de modelos de governança, novo serviço público e administração pública societal tem ganhado fôlego.

Conforme Secchi (2009, p. 358), as teorias do desenvolvimento tratam a governança como "um conjunto adequado de práticas democráticas e de gestão que ajudam os países a melhorar suas condições de desenvolvimento econômico e social". Segundo a Comissão Europeia, há cinco princípios cumulativos na base de uma boa governança: abertura, participação, accountability, efetividade e coerência 
(MAgalhães, 2011). Para Löffer (2001, p.212), citado por Kissler e Heidemann (2006), a governança pode ser entendida como:

uma nova geração de reformas administrativas e de Estado, que têm como objeto a ação conjunta, levada a efeito de forma eficaz, transparente e compartilhada, pelo Estado, pelas empresas e pela sociedade civil, visando uma solução inovadora dos problemas sociais e criando possibilidades e chances de um desenvolvimento futuro sustentável para todos os participantes (LÖFFER, 2001, p. 212, citado por KISSLER; HEIDEMANN, 2006).

Para Silva et al. (2013), a governança pública considera as interações interinstitucionais para a busca de melhores resultados da atuação governamental, enfatizando a efetividade das políticas públicas, assim como maior transparência das ações empreendidas com os recursos públicos para a sociedade.

O modelo societal proposto por Paula (2005) não difere muito dos critérios da governança pública, pois baseia-se na ênfase da dimensão sociopolítica, com grande relevância dada à participação social em processos decisórios de políticas públicas e a valorização de iniciativas locais. Já Denhardt (2012) aponta como alternativa à nova gestão pública o Novo Serviço Público. Entre as diretrizes do modelo, estão a reafirmação da democracia e da cidadania, a valorização das pessoas tidas como cidadãs em vez de consumidoras e a primazia do servir em vez do dirigir.

Os modelos construídos como alternativos ao gerencialismo tendem a incluir estratégias de descentralização política, adoção de mecanismos de responsabilização dos gestores (responsiveness e accountability), incremento do controle social, além de dispositivos de participação social que objetivam chamar cidadãos e organizações cívicas para atuarem como atores políticos da gestão pública (MILANI, 2008). Dessa forma, aponta-se para eminente busca pela efetividade, princípio em voga nesses modelos.

Demonstrada, assim, a correlação entre os modelos de administração pelos quais passou o País e os princípios de eficiência, eficácia e efetividade, deparase com a proposição de que as inovações do setor público em grande parte, senão por completo, sofreram e sofrem influência do contexto histórico em que surgem. Portanto, a formulação de uma proposta inovadora é reativa ao modelo administrativo vigente.

\section{Cruzamento}

Considerando o fato de que o espectro de tipologias de inovação é extenso e apresenta diversas opções de classificações e que originariamente foi desenvolvido para aplicação com finalidades de mercado, optou-se por realizar uma adaptação. 
Essa adaptação consiste em agrupar as tipologias existentes, reduzindo-as em três grandes categorias de inovações capazes de abarcar as principais vertentes de inovações no setor público. Não se pretende, contudo, esgotar as possibilidades de classificações, mas explorar possibilidades para compreender melhor a inovação no setor público.

As três categorias formadas compõem-se de inovações em serviço, inovações em arranjos organizacionais e, por fim, arranjos institucionais. Com elas cruzaram-se os momentos, conforme chamados por Coelho (2012) de primeira, segunda e terceira geração de inovações no setor público. Os momentos têm vínculo histórico com as fases que marcaram a evolução da administração pública desde a introdução da Administração Pública Burocrática. Entretanto, embora se pressuponha o vínculo histórico, considera-se que a realidade pode apresentar simultaneamente as três gerações, já que, embora haja um ordenamento no arranjo das gerações, isso não quer dizer que qualquer delas tenha sido extinta à medida que mudaram os paradigmas da administração pública. Admite-se, portanto, que, conforme muda o discurso que molda determinada época, muda também o enfoque privilegiado.

As categorias criadas para expressar os tipos de inovação no setor público (serviços, arranjos organizacionais e arranjos institucionais) podem reunir prováveis tipos de inovação tradicionalmente presentes na literatura, mas essa não foi uma condição essencial. Por exemplo, a inovação em produtos foi abarcada pelo tipo de serviços, uma vez que não há produção de bens no serviço público.

\section{Serviços}

A categoria da inovação em serviços abarca as inovações relacionadas com novas maneiras por meio das quais os serviços são providos pelos governos aos usuários (HARTLEY, 2005). Essas inovações se associam com o aumento da qualidade, de modo a promover o valor público (MOORE, 1995) dos serviços prestados. Conforme afirma Hartley (2005), a inovação em serviços é mais ambígua do que a inovação em produto, uma vez que ela usualmente não se materializa em torno de um artefato. A inovação em produto habitualmente ocorre por meio de empresas, as quais operam em ambiente de mercado.

A primeira geração de inovação em serviços se dá quando a introdução de novo serviço ou de melhorias nos serviços existentes promove mais eficiência no uso dos recursos públicos. Esse tipo de inovação pode ser exemplificado com a utilização das tecnologias de comunicação e informação para melhorar as condições de acesso do usuário ao serviço público, especialmente com o aproveitamento da internet como canal de prestação de serviços online. Tem-se, aí, o exemplo dos serviços de emissão de documentos online, como a emissão de certidão negativa de débitos 
(NASSUNO, 2000). Antes do serviço via internet, isso só se dava com a presença do usuário nos postos da agência recolhedora. Depois de realizada a solicitação, havia um prazo para a emissão do documento. Com a emissão online, o usuário tem acesso automaticamente à informação, sem onerar recursos humanos e físicos envolvidos no processo, com economia de tempo e dinheiro.

Ao relacionarmos a inovação em serviços inserida na segunda geração, é destacada a satisfação das necessidades da sociedade de modo mais amplo, e não apenas de necessidades do usuário de modo específico. Assim, busca-se a eficácia dos serviços prestados pelo governo como uma prioridade do interesse público. Um exemplo desse tipo de serviço é a vacinação que erradicou a varíola. Entretanto, como afirma Morel (2006), esse processo de erradicação por meio da prestação de serviço pelo Estado foi apenas o resultado de um complexo sistema de inovação que envolveu novo produto (vacina eficaz e de baixo custo), novo método (agulha bifurcada para inoculação de quantidade de vacina constante), novos processos (envolvimento das instâncias locais de aplicação de vacina) e nova estratégia (adoção da vacinação em círculos, em vez de vacinações em massa).

A terceira geração diz respeito ao modo de prestação de serviços que envolve a aproximação entre Estado e Sociedade, imprimindo uma dinâmica de construção contínua das relações democráticas. Toma-se como exemplo desse tipo de inovação o orçamento participativo digital da Prefeitura de Belo Horizonte. Conforme Sampaio et al. (2010), mesmo considerando baixos os índices de deliberatividade, a ferramenta consiste em uma política de participação popular através da internet que confere oportunidade aos cidadãos de fortalecerem efetivamente as suas trocas discursivas, melhorando suas condições de empoderamento no processo decisório do município.

\section{Arranjos organizacionais}

A categoria da inovação em arranjos organizacionais constitui-se das formas de organização interna do governo que visam melhorar os fluxos de comunicação, os processos de realização de tarefas e a estrutura organizacional, entre outras possibilidades (espaço de atendimento, polos, reengenharia de setores, etc.).

Sobre a inovação organizacional relacionada à primeira geração, cita-se a reestruturação organizacional inovadora onde os núcleos de trabalho são distribuídos de forma a obter uma estrutura organizacional mais eficiente e adaptada aos novos processos, sendo isso possibilitado por novas tecnologias. Uma análise dos efeitos das diversas formas de estruturas organizacionais pode ser vista no texto exemplar de Celso Furtado, publicado na Revista do Serviço Público (FURTADo, 1946). O foco se coloca sobre a eficiência organizacional. Há incontáveis maneiras de se promover 
mudanças na estrutura organizacional. Mas as que envolvem a primeira geração e, consequentemente, a busca de eficiência, restringem-se a alterações dentro dos limites da própria organização.

Na segunda geração, ao contrário da busca pela eficiência apenas no contexto organizacional, o foco está na gestão por resultados, que pressupõe a eficácia por meio de arranjos que mesclam organizações representantes do Estado e do mercado. Tal iniciativa pode ser percebida por meio dos novos arranjos organizacionais decorrentes da Nova Gestão Pública (Osborne; Gaebler, 1994; Bresser-PereirA, 2000). A administração pública gerencial apresentou como princípio a separação entre atividades exclusivas de Estado, atividades não exclusivas de Estado e atividades de mercado. Para realizar atividades não exclusivas, abriram-se possibilidades de novos formatos organizacionais com personalidade jurídica própria, como as organizações sociais. No que se refere à experiência gerencial no âmbito estadual, o choque de gestão de Minas Gerais (QUEIROZ; CKAGNAZAROFF, 2010) adotou medidas com o intuito de reter os gastos e reestruturar o desenho organizacional, inclusive com experiências inovadoras aplicadas, por exemplo, aos aspectos estratégicos, tecnológicos, estruturais e de controle.

A categoria dos arranjos organizacionais apresenta, como exemplo da terceira geração, as redes de cooperação da esfera pública, compostas não apenas por governo e mercado, mas também pela sociedade civil. Dias (2011) apresenta um estudo sobre essa espécie de arranjo, na qual a efetividade está fundada na legitimação social e no amplo debate para a realização do interesse público. Os novos modelos de governança que procuram aliar interesses de diversos atores em torno de objetivos comuns se inserem nesse escopo de inovações organizacionais. As redes de cooperação são exemplos desse tipo de arranjo, que procura integrar competências complementares na coprodução do bem comum.

\section{Arranjos institucionais}

A última categoria, denominada inovação em arranjos institucionais, é composta por inovações do tipo sociopolítico e conceitual, além das institucionais em si. São inovações que convergem por se tratarem da essência normativa e também cultural que rege o funcionamento das organizações no setor público e delimita a governabilidade dos atores do Estado. Além disso, as inovações inseridas nessa categoria estão relacionadas com o desenvolvimento de políticas que integram a participação popular, impactando positivamente sobre as necessidades e os direitos do cidadão. Como representam transformações sociais profundas, para se consolidarem, os novos arranjos institucionais passam por processos complexos. Tolber e Zucker (2007), por exemplo, afirmam que esses processos envolvem 
a habitualização de novas práticas, a objetivação que é a materialização dos significados que ocorrem, por exemplo, quando esquemas conceituais subjetivos são convertidos em coisas objetivas, e, por fim, a sedimentação, que é a reprodução das práticas como dados sociais que se perpetuam.

Referindo-se a arranjos institucionais alinhados à primeira geração, pressupõese a busca por uma racionalidade mais técnica com a preocupação recaída sob as regras das instituições, como a que foi implantada no período de burocratização do Brasil, em que a criação do Departamento Administrativo do Serviço Público (DASP) prefigura-se como marco importante (MENON, 2010). O DASP procurava organizar e racionalizar o serviço público, bem como elaborar a proposta do orçamento federal e a fiscalização orçamentária, compreendendo o papel do estado em seu aspecto legal-administrativo.

Sobre a perspectiva institucional com relação à segunda geração, é necessário destacar a influência do argumento da Nova Gestão Pública, que no Brasil foi traduzido por meio do Plano Diretor de Reforma do Aparelho de Estado. A perspectiva gerencialista pressupôs a possibilidade de novas formas de ação do Estado, com base em mudanças no caráter institucional-legal das regras e na mudança cultural de valores (BRESSER-PEREIRA, 2000). É propósito do modelo gerencial, assim, mudar a ênfase do controle burocrático para um controle sobre os resultados. Com isso, as inovações institucionais de segunda geração vão seguir ao lado das tentativas de tornar realidade o governo empreendedor focado em resultados, menos controlador dos meios e mais dos fins (OSBORNE; GAEBLER, 1995). Isso abre possibilidades de inovações institucionais significativas nas formas como o Estado controla seus gastos, realiza suas compras, responsabiliza os agentes públicos, desenha as funções e responsabilidades dos gestores, entre outras coisas. A Lei de Responsabilidade Fiscal é um exemplo de inovação institucional, a qual estabelece parâmetros para a realização do gasto público de cada ente federativo brasileiro. Esse novo arcabouço institucional tem proporcionado impactos positivos sobre as finanças públicas - veja, por exemplo, Linhares et al. (2013).

A citada categoria, no que tange à terceira geração de inovação, apresenta como pressuposto fundamental a busca de efetividade dos arranjos institucionais, visando sempre ao propósito de produzir resultados duradouros e relevantes nos contextos sobre os quais eles atuam. Como exemplo desse tipo de inovação está a justiça restaurativa, na qual as partes envolvidas atuam de maneira coletiva na restauração do dano causado, resultando num acordo alcançado que proponha respostas, tais como a reparação, a restituição e o serviço comunitário, objetivando atender às necessidades individuais e coletivas, bem como promover a reintegração da vítima e do ofensor (PRUDENTE; SABADELL, 2008). Outra prática essencial expoente 
dessa geração é o accountability. Na sua forma mais plena, o accountability é um instrumento que acaba por reorganizar os delineamentos institucionais das organizações públicas, no sentido de promover tanto uma mudança normativa, referente à criação de regras e leis que visam à responsabilização de atos dos governantes, quanto uma mudança cultural em duas frentes: direcionada aos cidadãos (orientados a manter estreita vigilância sobre o uso do poder concedido àqueles que foram escolhidos para governá-los) e direcionada aos governantes (que são impelidos a prestar contas das suas ações aos cidadãos que os escolheram) (ROCHA, 2011).

\section{Aplicação prática do diagrama analítico proposto}

Como aplicação prática do modelo apresentado, propositou-se, aqui, enquadrar as iniciativas premiadas do Concurso Inovação na Gestão Pública Federal da Enap. Para isso, estabelece-se uma restrição temporal de cinco anos, enquadrando duas iniciativas de cada ano do Concurso, de 2009 a 2013, escolhidas aleatoriamente. A análise dos casos para enquadramento se limitou à descrição exposta nos relatos enviados e publicados pela Enap; sendo assim, não se pretende analisar a inovação em si, mas a descrição da inovação conforme publicada. Na sequência, apresenta-se uma breve descrição de cada iniciativa e a justificativa do enquadramento proposto.

\section{Caso 1}

\section{Quadro 1 - Inovação em arranjos institucionais X eficácia}

\section{Concurso Inovação e Gestão Pública Federal da Enap (ENAP, 2010A)}

Experiência: Sistema Nacional de Gestão do Conhecimento em Segurança Pública

Data do início da experiência inovadora: agosto de 2003

O Sistema Nacional de Gestão do Conhecimento em Segurança Pública (SNGCSP) compõe um mecanismo institucional de incentivo à cooperação e articulação sistêmica entre os órgãos de segurança pública capaz de produzir o conhecimento necessário para subsidiar a execução de tarefas gerenciais. As iniciativas que baseiam o sistema são a criação de sistemas nacionais de coleta de dados, a modernização da infraestrutura de TI e qualificação dos profissionais para a produção desses dados e o desenvolvimento de insumos com a finalidade de auxiliar na distribuição de recursos do Fundo Nacional de Segurança Pública. Visando também consolidar a profissionalização na gestão das políticas de segurança pública federais, estaduais e municipais, e pautando a execução das ações e metas pela busca científica da solução de problemas, o SNGCSP orienta-se para diretrizes como qualidade das informações oficiais, a democratização do acesso às informações institucionais, administrativas e operacionais e renovação/modernização continuada dos órgãos de segurança pública. 
A iniciativa representa uma nova abordagem de enfrentamento dos problemas da segurança pública. As ações a partir da implantação do SNGCSP começaram a ser baseadas em diagnósticos e a distribuição de recursos passou a obedecer a um sistema de incentivos baseado em indicadores estatísticos. Paralelamente a isso, procurou-se difundir a cultura da transparência e divulgação de estatísticas criminais. O caso exemplifica uma iniciativa na Segunda Geração de Inovações (CoElHo, 2012) em arranjos institucionais, uma vez que as ações visavam institucionalizar a colaboração de diversas entidades no processo de coleta, sistematização, análise, divulgação e intercâmbio de dados, de modo a tornar as ações de segurança pública mais eficazes. A busca da eficácia se manifesta nas ações dos diversos órgãos envolvidos por meio da procura de estabelecer relação entre metas alcançadas e metas pretendidas (SANO; MonTENEGRO-FILHO, 2013). Isso se demonstra por meio da orientação para a profissionalização da gestão das ações de segurança pública, de modo a dar transparência para as informações dos indicadores de resultados cujo foco recai sobre a possibilidade de subsídio aos processos de planejamento e avaliação de resultados das políticas de segurança. Como discutido, o foco na eficácia é valorizado pela escola da Nova Gestão Pública (OSBORNE; GAEBLER, 1994), que também preza pela profissionalização da gestão, pelo planejamento estratégico e pelo controle eficaz.

\section{Quadro 2 - Inovação em arranjos organizacionais e arranjos institucionais X eficácia}

\section{Concurso Inovação e Gestão Pública Federal da Enap (2010a)}

Experiência: Rede Nacional de Altos Estudos em Segurança Pública (Renaesp)

Data do início da experiência inovadora: março de 2005

A Rede Nacional de Altos Estudos em Segurança Pública (Renaesp) atua como um projeto de educação permanente via promoção da pós-graduação na área de segurança pública. O objetivo principal da rede é democratizar o acesso dos profissionais de segurança pública aos processos de aprendizagem e aperfeiçoamento profissional, aproximando-os do universo acadêmico brasileiro. Efetiva-se a partir da parceria com instituições de ensino superior que recebem investimentos para realizar cursos nas modalidades presencial e a distância.

Fonte: Síntese de caso publicado (ENAP, 2010a).

O projeto com foco sob a educação permanente, democrática e qualificada visa fomentar a articulação entre instituições policiais e a formação acadêmica especializada a partir da perspectiva de um novo paradigma de segurança pública para o país comprometido com a cidadania e com os direitos humanos. Aponta, assim, para a "construção de uma cultura de segurança pública fundada nos paradigmas da modernidade, da inteligência, da informação e do exercício de competências estratégicas, técnicas e científicas" (ENAP, 2010a, p. 113). O programa 
capacita os agentes envolvidos direta ou indiretamente com segurança pública para atuarem em redes de colaboração, conforme aprofunda Dias (2011). Isso está de acordo com a categoria inovação em arranjos organizacionais. Entretanto, a partir do momento em que se predispõe a orientar as práticas policiais sob um novo paradigma de segurança pública, o qual pressupõe a mudança de valores e práticas da repressão para a prevenção, decorre-se um processo de institucionalização, nos moldes discutidos por Tolber e Zucker (2007). Isso caracteriza uma inovação de arranjos institucionais. A aproximação entre as práticas policiais e o conhecimento acadêmico do tema para geração de políticas públicas mais eficazes, no sentido de alcançar os propósitos predefinidos nas políticas e contribuir para o aperfeiçoamento da atuação dos profissionais de segurança pública, insere a iniciativa na segunda geração de inovações.

\section{Quadro 3 - Inovação em arranjos institucionais X eficiência e efetividade}

\section{Concurso Inovação e Gestão Pública Federal da Enap (2010b)}

Experiência: A Estratégia de Saúde da Família

Data do início da experiência inovadora: janeiro de 1994

O Saúde da Família representa uma estratégia com caráter substitutivo em relação à rede de atenção básica tradicional de saúde, na medida em que se efetiva por meio da reorientação do modelo assistencial, antes centrado na doença e agora respaldado pela valorização dos aspectos que influenciam a saúde das pessoas fora do ambiente hospitalar. A iniciativa é operacionalizada mediante a implantação de equipes multiprofissionais em unidades básicas de saúde responsáveis pelo acompanhamento de um número definido de famílias, localizadas em área geográfica delimitada. As equipes atuam com ações de promoção da saúde, prevenção, recuperação, reabilitação de doenças e agravos mais frequentes, e na manutenção da saúde dessa comunidade.

Fonte: Síntese de caso publicado (ENAP, 2010b).

A iniciativa enquadra-se na primeira geração - eficiência, conforme Coelho (2012) - de inovações em arranjos institucionais, já que aponta para reorganização do modelo de atenção tradicional vigente no País, o qual está centrado na doença, no assistencialismo e com ênfase no atendimento hospitalar e no uso de tecnologias de alto custo. O sistema inova na medida em que viabiliza o reordenamento do modelo de atenção no SUS, agora focado na atenção primária à saúde com o acompanhamento das famílias no sentido de prevenção de agravos, o que representa, então, maior racionalidade na utilização dos demais níveis assistenciais na rede especializada de serviços em saúde, melhorando a eficiência, de acordo com a definição do conceito feita por Sano e Montenegro-Filho (2013). Ademais, a questão do território adscrito permite o planejamento e a programação descentralizada, o que também aponta para economia e controle dos recursos. Como características secundárias a serem 
ressaltadas, cita-se o apoio a estratégias de fortalecimento da gestão local e do controle social e a procura de sinergia nas ações com outros setores de políticas públicas, o que representa um estágio intermediário entre os princípios da eficiência, cujo foco recai sobre a economia de recursos, e da efetividade, em que a participação social e a ação coletiva, mesmo entre as políticas, são enfocadas.

\section{Quadro 4 - Inovação em serviços X eficiência}

\section{Concurso Inovação e Gestão Pública Federal da Enap (2010b)}

Experiência: Programa Banda Larga nas Escolas

Data do início da experiência inovadora: abril de 2008

O Programa Banda Larga nas Escolas tem por objetivo a inclusão das tecnologias de informação e comunicação (TIC) na realidade das escolas públicas urbanas nacionais, sem ônus para os estados e municípios, via parceria público-privada, com duração dos serviços até 2025. O programa se efetivou mediante a troca de obrigações do Plano Geral de Metas de Universalização (PGMU) que, em 1997, "com a privatização das telecomunicações, imputou às operadoras a obrigação de instalação de postos de serviços telefônicos (PST) para atendimento e universalização do serviço de telefonia, situação que nunca atingiu os índices previstos" (ENAP, 2010, p. 117); sendo assim, a substituição da montagem dos PSTs pela infraestrutura necessária para o provimento de conexão à internet em alta velocidade (banda larga) em todos os municípios do Brasil representou troca de obrigações vantajosa à sociedade, que teve a oferta de serviço muito mais moderno de maneira mais rápida e eficaz.

Fonte: Síntese de caso publicado (ENAP, 2010b).

De acordo com a definição de Hartley (2005), a iniciativa é enquadrada na primeira geração de inovação em serviços. Trata-se de um novo serviço, antes não disponível, apesar de necessário. Na medida em que a articulação entre governo e iniciativa privada custeia a implantação e manutenção das conexões da internet sem ônus para os estados e municípios, a iniciativa se insere na primeira geração, visando, assim, à racionalidade de recursos, conforme ao que Sano e Montenegro-Filho (2013) atribuem ao conceito de eficiência, que é fazer mais com menos. Assim, a inovação na troca de obrigações pela dinâmica estabelecida entre governo e sociedades privadas em um modelo de parceria público-privada teve reflexo direto na condução e duração do programa, atingindo de maneira rápida o objetivo de propiciar conexões de ótima qualidade, garantia de renovação das tecnologias e disponibilidade dos serviços. O impacto indireto, portanto, em questões como evasão escolar e depreciação do ambiente e do material da escola, mas principalmente em relação à ascensão educacional, socialização da informação e formação cidadã é sentido mediante a adoção de um serviço cujo mecanismo utilizado para obtenção do êxito da ação estatal é baseado no uso de tecnologia aplicada à educação. 


\section{Quadro 5 - Inovação arranjos organizacionais X efetividade}

16 Concurso Inovação e Gestão Pública Federal da Enap (2011)

Experiência: O Censo Suas como Processo de Aprimoramento e Institucionalização da Política de Assistência Social no Brasil

Data do início da experiência inovadora: abril de 2007

O Censo Suas consiste num processo de monitoramento que coleta dados por meio de um formulário eletrônico preenchido pelas secretarias e conselhos de assistência social, cujo objetivo é aprimorar o processo de tomada de decisão e retroalimentar ações e projetos de assistência social, instituindo, assim, processos gradativos de adequação dos serviços às normas e de planejamento para melhoria da gestão e do controle social do Sistema Único de Assistência Social (Suas).

Fonte: Síntese de caso publicado (ENAP, 2011).

Trata-se de um "processo para o acompanhamento da efetividade da aplicação dos recursos federais e da qualidade da oferta dos serviços socioassistenciais" (ENAP, 2011, p. 90) baseado na participação e pactuação dos entes federados e envolvimento das instâncias de controle social. Assim, na medida em que o instrumento é pensado no sentido de aperfeiçoamento da gestão do Suas, da qualidade dos serviços prestados à população e da melhor articulação entre membros federados, a inovação se insere na terceira geração de arranjos organizacionais. A inovação em arranjos organizacionais é deduzida com base no fato de o processo envolver a reorganização das redes de colaboração entre esferas de governo e da sociedade, no sentido de construção de uma metodologia participativa e que favoreça o controle social. Conforme afirma Furtado (1946), a estrutura organizacional tem relação direta com a capacidade da organização de atingir seus objetivos. De outra forma, na medida em que a retroalimentação dos projetos e ações impacta na expansão da oferta e a melhoria da qualidade dos serviços prestados e na adoção e disseminação de padrões de referência para análise da qualidade das unidades e dos serviços, elucida-se, então, o viés de efetividade da iniciativa, uma vez que ilustra a "capacidade que os resultados têm de produzir mudanças duradouras e significativas" (OLIVEIRA, 2013, p. 29).

\section{Quadro 6 - Inovação em serviços X eficácia}

\section{6ㅇ Concurso Inovação e Gestão Pública Federal da Enap (2011)}

Experiência: Aviso para Requerimento de Benefício

Data do início da experiência inovadora: junho de 2009

O novo serviço caracterizado pelo envio do Aviso para Requerimento de Benefício aos segurados, contendo informações cadastrais, renda mensal estimada e orientações para agendamento do atendimento, materializa uma postura proativa da gestão, no sentido de identificar todos os segurados que implementariam o direito à aposentadoria por idade previamente à procura formulada pelos beneficiários, facilitando, assim, o acesso à informação de forma segura e prévia. Para sua viabilização, utilizam-se os dados constantes do Cadastro Nacional de Informações Sociais.

Fonte: Síntese de caso publicado (ENAP, 2011). 
Tendo em vista que o objetivo do Instituto Nacional do Seguro Social (INSS) é promover "o reconhecimento, pela Previdência Social, de direito ao recebimento de benefícios por ela administrados, assegurando agilidade, comodidade aos seus usuários (...)" (Decreto № 5.870/2006, art. 1ํㅡ, capítulo I, anexo I), a descrição da inovação constituída de envio do Aviso para Requerimento de Benefício aos segurados enquadra-se na categoria de serviços de segunda geração - eficácia, conforme Coelho (2012) -, já que o estabelecimento desse novo serviço permite o alcance dos resultados da organização relacionados com o conhecimento e a concessão dos direitos aos segurados. Como se elenca na iniciativa descrita, o objetivo do projeto de dar conhecimento ao segurado do direito à aposentadoria por idade foi alcançado, já que $83,11 \%$ dos segurados que receberam os avisos requereram o benefício, impactando, assim, diretamente nos resultados da organização.

\section{Quadro 7 - Inovação em serviços e arranjos organizacionais X efetividade}

\section{7ํㅡㄴ Concurso Inovação e Gestão Pública Federal da Enap (2013a)}

Experiência: Sistema de Gestão de Convênios e Contratos de Repasse (Siconv). Um Novo Paradigma nas Transferências Voluntárias da União

Data do início da experiência inovadora: setembro de 2008

O Sistema de Gestão de Convênios e Contratos de Repasse (Siconv) consiste num sistema de gestão responsável por todo o ciclo de vida dos convênios, contratos de repasse e termos de parceria, no qual são registrados os atos, desde a formalização da proposta até a prestação de contas final. O Siconv foi desenvolvido com a finalidade de consolidar uma base de integração mais clara e padronizada para todos os envolvidos, tornando o processo de transferências voluntárias mais transparente junto à sociedade civil (accountability) e atores envolvidos e reduzindo o custo operacional, já que se efetiva por meio da rede mundial de computadores.

Fonte: Síntese de caso publicado (ENAP, 2013a).

O Siconv enquadra-se na terceira geração das inovações em serviços. Tratase da implementação de novo sistema de gestão baseado nas premissas de democratização e equidade na distribuição dos recursos, com foco no controle social. No que diz respeito ao controle social, "a inovação trazida pelo Siconv possibilita a qualquer cidadão consultar as transferências voluntárias da União por meio da rede mundial de computadores, permitindo à sociedade o controle sobre a aplicação dos recursos públicos, em consonância com os princípios constitucionais insculpidos no caput do art. 37 da Constituição Federal” (ENAP, 2013a, p. 111). A iniciativa permite, assim, o usufruto dos benefícios sociais oriundos da boa e regular execução dos programas, o que impacta na melhoria de vida da sociedade. Outro aspecto que deve ser lembrado é que o sistema melhora a comunicação entre as entidades conveniadas, possibilitando a redução de assimetria de informações e estreitando as parcerias, provocando, assim, impacto no arranjo organizacional. 


\section{Quadro 8 - Inovação em arranjos institucionais X efetividade}

17음 Concurso Inovação e Gestão Pública Federal da Enap (2013a)

Experiência: Compromisso Nacional para Aperfeiçoar as Condições de Trabalho na Cana-de-Açúcar

Data do início da experiência inovadora: junho de 2009

O modelo de gestão inovador, baseado no diálogo e na intensa participação social dos atores envolvidos, intitulado como Compromisso Nacional para Aperfeiçoar as Condições de Trabalho na Cana-de-Açúcar, firmado pelo Governo Federal e entidades de trabalhadores e empresários do setor sucroenergético por meio de uma mesa de diálogo e resultante de negociação tripartite, tem objetivo de enfrentar o desafio de melhorar as condições de vida e trabalho no cultivo manual da cana-de-açúcar.

Fonte: Síntese de caso publicado (ENAP, 2013a).

O Compromisso Nacional para Aperfeiçoar as Condições de Trabalho na Canade-Açúcar promove a inovação por meio de um mecanismo conhecido como soft law, caracterizado por normatizar o comportamento dos atores de maneira a criar expectativas em relação à conduta daqueles que participam do processo decisório, utilizando, para isso, recomendações que incentivam a colaboração e união de esforços, fugindo, assim, de mecanismos com viés corretivo. Classifica-se, portanto, na categoria dos arranjos institucionais de terceira geração, já que institui novas formas de governança cujas premissas são o diálogo/ integração entre atores e a participação social, o que acaba por induzir os demais atores do setor econômico a adotar de forma voluntária as práticas previstas pelo compromisso.

\section{Quadro 9 - Inovação em arranjos organizacionais X eficiência}

18 Concurso Inovação e Gestão Pública Federal da Enap (2013b)

Experiência: Novo Processo de Análise de Atos de Concentração Econômica

Data do início da experiência inovadora: maio de 2007

O novo processo de análise de atos de concentração econômica trata das soluções implementadas para reformular e adequar à Lei no $12.529 / 2011$ o processo de análise de compras e fusões entre empresas, agora unificado no Conselho Administrativo de Defesa Econômica (Cade). Diante de gargalos identificados no processo de adequação à referida lei, necessitava-se implementar um novo sistema de análise de operações e reduzir drasticamente o tempo de análise, mantendo a qualidade da instrução dos casos. Assim, a iniciativa inovadora alterou a forma de gestão dos processos de análise de atos de concentração desde sua identificação até sua decisão final, promovendo organização mais eficiente do trabalho via criação de unidade responsável pela triagem dos técnicos, divisão funcional e por setor da economia na estrutura da Superintendência-Geral, revisão dos critérios de apresentação das operações e aplicação de técnicas de gestão de projetos e monitoramento.

Fonte: Síntese de caso publicado (ENAP, 2013b). 
A iniciativa acima descrita se insere, portanto, na primeira geração das inovações em arranjos organizacionais, já que representa nova estruturação que impacta no trâmite processual de trabalho, produzindo efeito direto sobre o uso eficiente do tempo e dos recursos materiais/humanos do conselho. Assim, o processo de triagem e análise dos casos por grau de complexidade representou drástica redução de tempo de análise, bem como a divisão funcional da estrutura. Ademais, a utilização de técnicas de gestão de projetos também gerou economia significativa de recursos. Como citado no relato do caso, a iniciativa foi capaz de "revolucionar o processo de análise de fusões e aquisições no Cade de forma rápida e com custos irrisórios".

\section{Tabela 2 - Categorias de inovação versus gerações de inovação}

\begin{tabular}{|c|c|c|c|}
\hline $\begin{array}{l}\text { Gerações } \\
\text { Categorias }\end{array}$ & $\begin{array}{l}\text { Primeira geração } \\
\text { (eficiência) }\end{array}$ & $\begin{array}{l}\text { Segunda geração } \\
\text { (eficácia) }\end{array}$ & $\begin{array}{l}\text { Terceira geração } \\
\text { (efetividade) }\end{array}$ \\
\hline Serviço & $\begin{array}{l}\text { Novo serviço que } \\
\text { permite reduzir custos } \\
\text { e/ou racionalizar re- } \\
\text { cursos empregados. } \\
\text { Ex.: Programa Banda } \\
\text { Larga nas Escolas }\end{array}$ & $\begin{array}{l}\text { Novo serviço que } \\
\text { contribui para a } \\
\text { realização plena dos } \\
\text { objetivos públicos e } \\
\text { organizacionais. } \\
\text { Ex.: Aviso para } \\
\text { Requerimento de } \\
\text { Benefício-INSS }\end{array}$ & $\begin{array}{l}\text { Novo serviço que } \\
\text { melhora a qualidade } \\
\text { da ação pública por } \\
\text { meio da relação apro- } \\
\text { ximada entre Estado e } \\
\text { sociedade. } \\
\text { Siconv }\end{array}$ \\
\hline $\begin{array}{l}\text { Arranjos orga- } \\
\text { nizacionais }\end{array}$ & $\begin{array}{l}\text { Novo arranjo organiza- } \\
\text { cional que permite } \\
\text { reduzir custos e/ou } \\
\text { racionalizar recursos } \\
\text { empregados. } \\
\text { Ex.: processo de análi- } \\
\text { se de atos de concen- } \\
\text { tração econômica }\end{array}$ & $\begin{array}{l}\text { Novo arranjo organiza- } \\
\text { cional que contribui } \\
\text { para a realização ple- } \\
\text { na dos objetivos públi- } \\
\text { cos e organizacionais. } \\
\text { Rede Nacional de } \\
\text { Altos Estudos em } \\
\text { Segurança Pública } \\
\text { (Renaesp) }\end{array}$ & $\begin{array}{l}\text { Novo arranjo organiza- } \\
\text { cional que melhora } \\
\text { a qualidade da ação } \\
\text { pública por meio da } \\
\text { relação aproxima- } \\
\text { da entre Estado e } \\
\text { sociedade. } \\
\text { Ex.: Censo Suas }\end{array}$ \\
\hline $\begin{array}{l}\text { Arranjos } \\
\text { institucionais }\end{array}$ & $\begin{array}{l}\text { Novo arranjo que } \\
\text { permite reduzir custos } \\
\text { e/ou racionalizar re- } \\
\text { cursos empregados. } \\
\text { Ex. Saúde da Família }\end{array}$ & $\begin{array}{l}\text { Novo arranjo institu- } \\
\text { cional que contribui } \\
\text { para a realização ple- } \\
\text { na dos objetivos públi- } \\
\text { cos e organizacionais. } \\
\text { Ex.: Sistema Nacional } \\
\text { de Gestão do } \\
\text { Conhecimento em } \\
\text { Segurança Pública } \\
\text { (SNGCSP) }\end{array}$ & $\begin{array}{l}\text { Novo arranjo institu- } \\
\text { cional que melhora } \\
\text { a qualidade da ação } \\
\text { pública por meio da } \\
\text { relação aproxima- } \\
\text { da entre Estado e } \\
\text { sociedade. } \\
\text { Ex.: Compromisso } \\
\text { Nacional para } \\
\text { Aperfeiçoar as } \\
\text { Condições de Trabalho } \\
\text { na Cana-de-Açúcar }\end{array}$ \\
\hline
\end{tabular}

Fonte: Elaborado pelos autores. 


\section{Conclusões}

Neste artigo, o objetivo foi o de realizar um estudo exploratório da inovação no setor público, propondo um modelo analítico de tipologias e categorias de inovação específicas desse contexto. Para isso, foram identificadas categorias de inovação vastamente investigadas em ambiente de mercado, antes de estabelecer pontos de convergência desse arcabouço prévio com o ambiente público. A introdução de conceitos que dizem respeito à teoria e à prática da administração pública contribuíram para a demarcação de categorias específicas de inovação no setor público: (i) serviços; (ii) arranjos organizacionais e (iii) arranjos institucionais. Partimos do pressuposto de que essas tipologias se manifestam sob ênfases distintas, as quais, assim como Coelho (2012), consideramos como inovações de primeira, de segunda e de terceira geração. Elas dizem respeito, respectivamente, aos conceitos de eficiência, eficácia e efetividade. Uma diferença fundamental que deve ser lembrada quando se pretende analisar a inovação no contexto público está relacionada com o que Moore (1995) chama valor público. Diferentemente do setor privado, que habitualmente inova como meio de sobrevivência em ambiente competitivo, a inovação no setor público precisa criar valor público, de modo a acomodar os interesses públicos e produzir bem coletivo.

Por suas características próprias, o Estado não deixa de existir pela falta de inovação, diferente do que acontece a várias empresas. Todavia, a perpetuação de um Estado pouco inovador conduz a um Estado distanciado da sociedade. Essa situação é insustentável, uma vez que a tendência é o crescimento da insatisfação e das exigências pelo atendimento das demandas sociais. Assim, a inovação é essencial para que o Estado se transforme para realizar suas funções de modo pleno.

Entre os principais resultados, foi possível observar a interposição de três variáveis exploradas ao longo do trabalho como principais influenciadoras da formulação das tipologias de inovação voltadas ao contexto do setor público: as três gerações de inovação. O cruzamento das categorias com as gerações possibilitou uma leitura complexa do fenômeno da inovação no setor público, o qual se manifesta de diversas formas, num vasto espectro de possibilidades que ultrapassam modelos estáticos distanciados do cotidiano das organizações públicas.

Tendo em vista o aspecto difuso das tipologias formuladas, integram-se os principais eixos do presente ensaio num diagrama analítico que permite classificar as diferentes iniciativas inovadoras no âmbito do setor público: as gerações de inovação (que, conforme evolução histórica dos modelos de gestão, têm seus enfoques favorecidos) e as tipologias de inovação (agora agrupadas nas categorias de inovação em serviços, arranjos organizacionais e arranjos institucionais). 
Lembra-se que o modelo resultante no presente ensaio é uma aproximação, um estudo ainda exploratório sobre tema que, conforme se buscou demonstrar, ocupa espaço de importância no debate atual da administração pública. Como estudo exploratório, é um estudo ainda limitado, que não tem a pretensão de apresentar um modelo completo e final. Além disso, o uso das descrições dos casos do concurso é limitado por não apresentar todas as respostas necessárias para uma classificação plenamente adequada. Como implicações dessa proposta, elenca-se a sua principal contribuição, que é descortinar possibilidades de construção de um sistema que facilite a classificação das diferentes ações inovadoras no setor público, o que pode contribuir para fomentar a busca de aprofundamento teórico, como para orientar ações que incentivem essas práticas. O enquadramento exemplificativo dos casos do Concurso Inovação na Gestão Pública Federal possibilitou evidências que sugerem a aplicabilidade do modelo. A respeito disso, é necessário afirmar que as características multifacetadas dos casos analisados ocasionaram certa dificuldade de enquadrá-los apenas sob perspectivas uníssonas. Embora isso possa representar um problema, percebe-se, contudo, que a continuidade do estudo é necessária para ampliar a compreensão sobre esse tema relevante.

\section{Referências bibliográficas}

AlberTI, Adriana; BeRTUCCI, Guido. Replicating innovations in governance: an overview. In: UNITED NATIONS. Innovations in governance and public administration: replicating what works. New York, 2006.

ANDREASSI, T. Gestão da inovação tecnológica. São Paulo: ThomsonLearning, 2007. ARAgÃo, Cecília Vescovi de. Burocracia, eficiência e modelos de gestão pública: um ensaio. Revista do Serviço Público, ano 48, no 3, set.-dez. 1997.

BARACCHINI, Sabrina Addison. A inovação presente na administração pública brasileira. Revista de Administração de Empresas., v. 42, n. 2, São Paulo, Apr./June, 2002.

BARLACH, Lisete. Liderança e inovação na administração pública. Revista Gestão \& Políticas Públicas, v. 2, n. 1, 2012.

BRANDÃo, S.; BRUNO-FARIA, M. Inovação no setor público: análise da produção científica em periódicos nacionais e internacionais da área de administração. Revista de Administração Pública, Brasil, v. 47, n.1, jan. 2013.

BRASIL. Presidência da República (F.H. Cardoso), 1995. Plano Diretor da Reforma do Aparelho do Estado. Brasília: Presidência da República, Câmara da Reforma do Estado. Ministério da Administração Federal e Reforma do Estado, 1995.

BRASIL. Concurso Inovação na Gestão Pública Federal. Disponível em: <http:// inovacao.enap.gov.br>. Acesso em: 05 out. 2015.

BResser-PereirA, L. C. Estratégia e estrutura para um novo Estado. Revista de Economia Política, v. 17, n. 3, jul.-set., 1997, p. 24-38. 
Bresser-PereirA, L. C. A reforma gerencial do estado de 1995. Revista de Administração Pública, v. 34, n. 4. Julho, 2000, p. 55-72.

Coelho, F. S. Reformas e Inovações na Gestão Pública no Brasil Contemporâneo. In: Denhardt, R. B. Teorias da Administração Pública. São Paulo: Cengage Learning, 2012. DIAS, C. N. Redes de cooperação social como estratégia para a implementação de políticas públicas: o caso da PNDR. V ENCONTRO DE ESTUDOS EM ESTRATÉGIA. Anais. Porto Alegre, 15-17 de maio, 2011.

EnAP. Ações premiadas no 14 Concurso Inovação na Gestão Pública Federal - 2009. - Brasília: Enap, 2010a.

EnAP. Ações premiadas no 15 Concurso Inovação na Gestão Pública Federal - 2010. Brasília: Enap, 2010b.

EnAP. Ações premiadas no 16 Concurso Inovação na Gestão Pública Federal-2011. - Brasília: Enap, 2011.

EnAP. Ações premiadas no 17ํ Concurso Inovação na Gestão Pública Federal - 2012. Organizado por Flavio Schettini Pereira- Brasília: Enap, 2013a

EnAP. Ações premiadas no 18 Concurso Inovação na Gestão Pública Federal - 2013. Organizado por Flavio Schettini Pereira- Brasília: Enap, 2013b.

ENAP. Ações premiadas no 19 Concurso Inovação na Gestão Pública Federal - 2014. Organizado por Flavio Schettini Pereira- Brasília: Enap, 2014.FARAH, Marta Ferreira Santos. Disseminação de políticas públicas e programas governamentais no nível subnacional de governo. Revista Administração e Diálogo, n.11, v. 2, 2008, p. 69-89. Furtado, Celso M. Teoria da estrutura em organização. Revista do Serviço Público, v. 1, ano 9, n. 2, 1946, p. 17-26.

HARTLEY, Jean. Innovation in governance and public services: past and present. Public Money \& Management, n. 25, v. 1, p. 27-34, 2005.

JUnquilho, Gelson Silva. Teoria da Administração Pública. Florianópolis: Departamento de Ciências da Administração / UFSC. Brasília: CAPES: UAB, 2010.

KISSLER, L.; HEIDEMANN, F. G. Governança pública: novo modelo regulatório para as relações entre Estado, mercado e sociedade? Revista de Administração Pública, Brasil, v. 40, n. 3, mai./jun. 2006.

KOCH, P.; HAUKNES, J. Innovation in the public sector. Publin Report n. D20. Oslo: NIFU STEP, 2005. Disponível em: <https://brage.bibsys.no/xmlui/bitstream/ handle/11250/226573/d20-innovation.pdf?sequence=1 >. Acesso em: 1 jun. 2016.

LIMA, D.; VARGAS, E. Estudos internacionais sobre inovação no setor público: como a teoria da inovação em serviços pode contribuir? Revista de Administração Pública, Brasil, v. 46, n. 2, mar./abr. 2012.

Linhares, Fabricio; Penna, Christiano; Borges, Glenda. Os efeitos da Lei de Responsabilidade Fiscal no endividamento dos municípios do Piauí. Revista de Administração Pública, Rio de Janeiro, v. 47, n. 6, 2013, p. 1359-1373.

LÖFFER, Elke. Governance: Die neue Generation von Staats- und Verwaltungsmodernisierung. Verwaltung + Management, v. 7, n. 4, p. 212-215, 2001. 
MAgalhãEs, Renata Silva Pugas. Governança em organizações Públicas- desafios para entender os fatores críticos de sucesso: o caso do Tribunal de Contas da União. Artigo (Especialização em Planejamento, Orçamento e Gestão Pública), Fundação Getúlio Vargas, Brasília, 2011.

MENON, G. A tentativa de racionalização do estado brasileiro na era Vargas: uma breve análise sobre o DASP. Revista FIDES, v. 1, n. 2, ago.-dez., 2010, p. 154-167.

MILANI, C. O princípio da participação social na gestão de políticas públicas locais: uma análise de experiências latino-americanas e europeias. Revista de Administração Pública, Brasil, v. 42, ago. 2008.

MoORE, M. H. Creating public value: strategic management in government. Harvard University Press, Cambridge, 1995.

Morals, Janaina Jacolina. Princípio da eficiência na Administração Pública. Disponível em: < http://www.eduvaleavare.com.br/ethosjus/revista3/pdf/principio _eficiencia.pdf>. pp. 5/6. Acesso em: 04 Fev. 2014.

MoRel, C. M. Inovação em saúde e doenças negligenciadas. Cadernos de Saúde Pública, Rio de Janeiro, n. 22, v. 8, p. 1522-1523, ago. 2006.

MotTA, Paulo Roberto Mendonça. O estado da arte da gestão pública. Revista de Administração de Empresas, São Paulo, v. 53, n. 1, jan.-fev., 2013, p. 82-90.

MulgaN, G.; AlBuRY, D. Innovation in the Public Sector Discussion paper, London: Cabinet Office Government, 2003.

NASSUNO, Marianne. A administração com foco no usuário-cidadão: realizações no governo federal brasileiro nos últimos 5 anos. Revista do Serviço Público, v. 51, n. 4, 2000, p. 61-98.

OliveirA, Vanessa Elias de. As fases do processo de políticas públicas. In: Políticas públicas em debate. São Bernardo do Campo, SP: MP Editora, 2013. 320p.

OSBORNE, David; GAEBLER, Ted. Reinventandoogoverno: como o espírito empreendedor está transformando o setor público. Brasília: MH Comunicação, 1994.

PAULA, Ana Paula Paes de. Por uma nova gestão pública: limites e potencialidades da experiência contemporânea. Rio de Janeiro: Editora GV, 2005.

Prudente, N.; SABAdell, A. Mudança de paradigma: justiça restaurativa. Revista Jurídica Cesumar - Mestrado, América do Norte, v. 8, jul. 2008.

QueIROZ, R. G. M.; CKAgnaZAROFF, I. B. Inovação no setor público: uma análise do choque de gestão (2003-2010) sob a ótica dos servidores e dos preceitos teóricos relacionados à inovação no setor público. Revista de Administração Pública, n. 44, v. 3, maio-junho, 2010, p. 679-705.

RocHA, Arlindo Carvalho. Accountability na Administração Pública: modelos teóricos e abordagens. Contabilidade, Gestão e Governança, Brasília, v. 14, n. 2, 2011, p. $82-97$.

SAMPAIO, Rafael Cardoso; MAIA, Rousiley Celi Moreira; MARQUES, Francisco Paulo Jamil Almeida. Participação e deliberação na internet: um estudo de caso do Orçamento Participativo Digital de Belo Horizonte. Opin. Publica [online], v.16, n. 2, 2010, p. 446-477. 
SANDAMAS, Claire. Innovation in public services: literature review. Innovation Fórum, 2005. Disponível em: < http://www.idea.gov.uk/idk/aio/1118552>. Acesso em: 25 Abril 2014.

SANo, Hironobu; Montenegro-Filho, Mário Jorge França. As técnicas de avaliação da eficiência, eficácia e efetividade na Gestão Pública e sua relevância para o desenvolvimento social e das ações públicas. Desenvolvimento em Questão, v. 11, n. 22, 2013, p. 35-61.

SCHUMPETER, Joseph Alois. Teoria do Desenvolvimento Econômico: uma investigação sobre lucros, capital, crédito, juro e o ciclo econômico. São Paulo: Abril Cultura, 1982.

SECCHI, L. Modelos organizacionais e reformas da administração pública. Revista de Administração Pública, Brasil, vol. 43, out. 2009.

Silva, F. De A.; Martins, T. C. P. M.; CKagnazaroff, I. B. Redes organizacionais no contexto da governança pública: a experiência dos Tribunais de Contas do Brasil com o grupo de planejamento organizacional. Revista do Serviço Público, Brasília, v. 64, n. 2, 2013, p. 249-271.

SPINK, Peter. A inovação na perspectiva dos inovadores. Cadernos EBAPE, Rio de Janeiro, v. 1, n. 2, p. 01-13, dez. 2003.

TOLBERT, Pamela S.; ZUCKER, Lynne G. A institucionalização da teoria institucional. In: ClegG, Stewart R.; HARDY, Cynthia; NoRD, Walter (Orgs.). Handbook de estudos organizacionais. São Paulo: Atlas, 2007.

\section{Dany Flávio Tonelli}

Doutor em Administração, professor e pesquisador no Programa de Pós-graduação em Administração Pública e na graduação em Administração Pública da Universidade Federal de Lavras. Atualmente é pró-reitor adjunto de Extensão e Cultura na mesma universidade.

Contato: danytonelli@dae.ufla.br

\section{Samantha Thais Baião Moreira}

Graduanda em Administração Pública pela Universidade Federal de Lavras. Diretora de Projetos e Comunicação no Centro Acadêmico de Administração Pública - CenAAP/UFLA.

Contato: samanthamoreira11@yahoo.com

lasmim Mesquita

Graduada em Administração Pública. Atualmente participa de processo seletivo para mestrado em Gestão Pública. Contato: iasmimmesquita11@hotmail.com

Stephania Rezende Silva

Graduada em Administração Pública.

Contato: stephaniarezende1994@gmail.com

Maria Olívia Silva e Vasques

Graduação em Administração Pública. Atualmente é mestranda em Administração, na área de concentração Gestão de Negócios, Economia e Mercados.

Contato: olivia_vasques1@hotmail.com 